\title{
Racial and Ethnic Disparities in Cancer Screening
}

\author{
The Importance of Foreign Birth as a Barrier to Care
}

Mita Sanghavi Goel, MD, Christina C. Wee, MD, MPH, Ellen P. McCarthy, PhD, MPH, Roger B. Davis, ScD, Quyen Ngo-Metzger, MD, MPH, Russell S. Phillips, MD

CONTEXT: Racial/ethnic groups comprised largely of foreignborn individuals have lower rates of cancer screening than white Americans. Little is known about whether these disparities are related primarily to their race/ethnicity or birthplace.

OBJECTIVE: To determine whether foreign birthplace explains some racial/ethnic disparities in cancer screening.

DESIGN, SETTING, AND SUBJECTS: Cross-sectional study using 1998 data from the National Health Interview Survey.

MAIN OUTCOME MEASURES: Completion of cervical, breast, or colorectal cancer screening.

RESULTS: Of respondents, $15 \%$ were foreign born. In analyses adjusted for sociodemographic characteristics and illness burden, black respondents were as or more likely to report cancer screening than white respondents; however, Hispanic and Asian-American and Pacific Islander (AAPI) respondents were significantly less likely to report screening for most cancers. When race/ethnicity and birthplace were considered together, U.S.-born Hispanic and AAPI respondents were as likely to report cancer screening as U.S.-born whites; however, foreignborn white (adjusted odds ratio [AOR], 0.58; 95\% confidence interval [CI], 0.41 to 0.82), Hispanic (AOR, 0.65; 95\% CI, 0.53 to 0.79), and AAPI respondents (AOR, 0.28; 95\% CI, 0.19 to 0.39) were less likely than U.S.-born whites to report Pap smears. Foreign-born Hispanic and AAPI respondents were also less likely to report fecal occult blood testing (FOBT); AORs, $0.72 ; 95 \% \mathrm{CI}, 0.53$ to 0.98 ; and $0.61 ; 95 \% \mathrm{CI}, 0.39$ to 0.96 , respectively); and sigmoidoscopy (AORs, $0.70 ; 95 \% \mathrm{CI}, 0.51$ to 0.97 ; and $0.63 ; 95 \% \mathrm{CI}, 0.40$ to 0.99 , respectively). Furthermore, foreign-born AAPI respondents were less likely to report mammography (AOR, 0.49; 95\% CI, 0.28 to 0.86). Adjusting for access to care partially attenuated disparities among foreign-born respondents.

CONCLUSION: Foreign birthplace may explain some disparities previously attributed to race or ethnicity, and is an important barrier to cancer screening, even after adjustment for other

Received from the Division of General Medicine and Primary Care, Department of Medicine, Beth Israel Deaconess Medical Center, Harvard Medical School (MSG, CCW, EPM, RBD, QN-M, RSP), Boston, Mass.

Address correspondence and requests for reprints to Dr. Goel: Beth Israel Deaconess Medical Center, 330 Brookline Avenue, Boston, MA 02215 (email: mgoel@caregroup.harvard.edu). factors. Increasing access to health care may improve disparities among foreign-born persons to some degree, but further study is needed to understand other barriers to screening among the foreign-born.

KEY WORDS: cervical cancer; breast cancer; colorectal cancer; cancer screening; race/ethnicity; immigrant status; health disparities.

J GEN INTERN MED 2003; 18:1028-1035.

A pproximately 1 in 10 people currently living in the United States was born abroad. An estimated 28.4 million foreign-born individuals resided in the United States in 2000, increasing from 9.6 million in 1970. Over time, the proportion of foreign-born individuals, especially Hispanic and Asian-American and Pacific Islander, is expected to continue increasing. ${ }^{1}$

Small studies of racial and ethnic subgroups comprised largely of immigrants show they have lower screening rates for cervical, breast, and colorectal cancer. ${ }^{2-7}$ In particular, Hispanics and Asian Americans and Pacific Islanders have lower screening rates than whites for cervical, breast, and colorectal cancers. $^{8-12}$ While many have attributed such disparities to differences in "race" and "ethnicity," few studies have examined whether these differences in screening rates are explained by immigration status or foreign birth. Furthermore, possible reasons for disparities by birthplace are unclear, although previous literature suggests that foreign-born persons are more likely to encounter barriers related to health care access, such as lack of insurance. ${ }^{13,14}$ Additionally, foreign-born individuals are more likely to encounter language and cultural barriers, which have been shown to affect communication with providers. ${ }^{9,15-18}$ To our knowledge, no studies have examined the effects of birthplace on cancer screening using nationally representative data or evaluated the combined effects of foreign birthplace and race/ethnicity on cancer screening.

In this context, we used a nationally representative database to examine whether foreign birthplace can explain racial/ethnic disparities in cancer screening. Additionally, we examined the role of access to care in attenuating differences by race/ethnicity and birthplace. 


\section{METHODS}

\section{Data Source}

We used data collected from the 1998 National Health Interview Survey (NHIS), an in-person health survey of the civilian, noninstitutionalized population administered by the U.S. Bureau of the Census for the National Center for Health Statistics. ${ }^{19}$ A total of 98,785 respondents from 38,209 households provided information about sociodemographics, including country of birth, indicators of health status, and utilization of health services, yielding a response rate of $90 \%$. One randomly selected adult per household 18 years or older also completed the Sample Adult and Sample Adult Prevention modules, which elicited information on health status, health care services and behavior, and cancer screening. The response rate for this portion of the survey was $84 \%(n=32,440)$. The combined response rate to both components of the survey was $74 \%$. The survey is administered in only Spanish and English and does not allow proxies to respond to cancer screening questions. Family members may translate for a non-English, non-Spanish speaking respondent present in the home.

\section{Outcomes of Interest}

We had 3 outcomes of interest: cervical cancer screening, breast cancer screening, and colorectal cancer screening. We defined adherence to screening for all 3 cancers based on the recommendations of the United States Preventative Services Task Force (USPSTF). ${ }^{20}$

For cervical cancer screening, we studied women aged 18 to 65 years who had not undergone a hysterectomy. Women were considered screened if they reported having a Papanicolaou (Pap) smear in the previous 3 years.

For breast cancer screening, we studied women aged 50 to 74 years, and considered women screened if they reported having a mammogram in the previous 2 years.

For colorectal cancer screening, we studied fecal occult blood testing (FOBT) and flexible sigmoidoscopy in men and women aged over 50 years. We considered respondents screened if they reported FOBT in the previous year. Because no specific questions for flexible sigmoidoscopy or colonoscopy exist in the NHIS interview, we used the question, "A proctoscopic exam is when a tube is inserted in the rectum to check for problems. Have you ever had a proctoscopic exam?" as a proxy for sigmoidoscopy. An individual was considered screened if proctoscopy (sigmoidoscopy) was completed in the previous 5 years.

\section{Race/Ethnicity, Birthplace, and Other Factors of Interest}

The first main factor of interest was race and ethnicity. Race and ethnicity were categorized as non-Hispanic white, non-Hispanic black, Hispanic, or Asian-American and Pacific Islander (AAPI). The second main factor of interest was foreign birth, which we considered a proxy for immigrant status. We defined foreign birth as birthplace either in a
U.S. territory or outside of the United States, asking, "In what country were you born?" Since the survey already categorized those respondents born in U.S. territories as foreign-born, and since we felt that those respondents were culturally most similar to the foreign-born respondents, we felt they could satisfactorily be grouped together.

We also considered other factors such as sociodemographic characteristics, illness burden, and measures of access to health care. We defined sociodemographic characteristics as age (in decades), marital status (married, never married, widowed/divorced/separated, living with partner), region of residence (Northeast, Midwest, South, West), level of education (less than high school education, high school graduate, some post-high school education, college graduate or beyond), and annual household income $(<\$ 20,000, \geq \$ 20,000)$. We defined illness burden as selfreported health status (excellent, very good, good, fair, poor), smoking status (never, current, past), presence of concurrent illnesses (hypertension, myocardial infarction/ stroke, chronic obstructive pulmonary disease/asthma, diabetes, joint or back pain, renal/liver disease, history of cancer), body mass index (BMI; underweight $\left[<18.5 \mathrm{~kg} / \mathrm{m}^{2}\right]$, normal [18.5-25 kg/m ${ }^{2}$, overweight [25-30 kg/m ${ }^{2}$ ], obese $\left.\left[\geq 30 \mathrm{~kg} / \mathrm{m}^{2}\right]\right)$, and hospitalizations in the past year $(0,1, \geq 2)$.

We hypothesized that access to care would attenuate any relationship between foreign birthplace and cancer screening. We measured access to care using number of office visits in the past year (none, 1, 2-3, 4-9, $\geq 10$ ), type of health insurance (uninsured, Medicare, Medicaid, private health maintenance organization, private fee-for-service), and usual source of care (general practitioner, obstetrician/ gynecologist, specialist, no usual provider but usual source of care, no usual source of care).

\section{Statistical Analysis}

We conducted bivariable analyses comparing baseline characteristics between foreign-born and U.S.-born individuals, and compared screening rates across race/ethnicity and birthplace. We used $\chi^{2}$ statistics for all categorical variables and a $t$ test for continuous variables.

We then described the association between race/ ethnicity and cancer screening by fitting multivariable logistic regression models for each outcome of interest (screening for cervical, breast, and colorectal cancer). Our initial analyses used race/ethnicity as the major independent variable. We adjusted for potential confounders previously described in the literature, including sociodemographic characteristics (age, marital status, region of residence, education, annual household income) and illness burden (self-reported health status, smoking status, concurrent illnesses, BMI, and hospitalizations in the past year). Prior to inclusion of the independent variables education and income, as well as concurrent illness, hospitalizations, and number of visits, we checked for collinearity. If the change in standard error was less than 10\% after serial addition into the adjusted models, we included the variables in all 
adjusted statistical models. Additionally, because the temporal relationship between cancer diagnosis and screening was not available, we adjusted for cancers not directly related to the outcome of interest to avoid overadjusting. For cervical cancer screening, we adjusted for nongynecologic cancers. For breast cancer screening, we adjusted for nonbreast cancers. For colorectal cancer screening, we adjusted for noncolorectal cancers.

To examine whether birthplace explained racial/ethnic differences in cancer screening, we created a variable combining race/ethnicity and birthplace (U.S.-born white, foreign-born white, U.S.-born black, foreign-born black, U.S.-born Hispanic, foreign-born Hispanic, U.S.-born AAPI, foreign-born AAPI). We then fit a series of models comparing cancer screening between U.S.-born white persons (reference) and other groups. We performed a 2-step analysis, first adjusting for sociodemographic characteristics and illness burden, and then for access to care (number of office visits in the past year, type of health insurance, usual source of care) to explore whether accounting for access to care explained differences by race/ethnicity and foreign birthplace.

Last, we performed separate analyses focusing on the largest foreign-born populations in the United States, Hispanic and AAPI persons. We compared foreign-born Hispanic and AAPI respondents with their respective U.S.-born counterparts to isolate the effects of foreign birthplace. We subsequently repeated the same 2-step logistic regression analyses described previously, first examining the effects of sociodemographic characteristics and illness burden, and then access to care.

For all analyses, data were weighted to reflect national population estimates and analyzed using SAS-callable SUDAAN software, version 7.5 (Research Triangle Institute, Research Triangle Park, NC), to adjust for the sampling scheme. ${ }^{21}$ We considered a 2 -tailed $P$ value of $\leq 0.05$ statistically significant for all analyses.

\section{RESULTS}

\section{Unadjusted Comparisons}

The 32,440 respondents completing the Adult Prevention module represented more than 195 million people in the United States. Of these respondents, 15\% were foreign born. Table 1 compares the baseline characteristics between U.S.born and foreign-born respondents using weighted analyses. All sociodemographic factors measured were significantly different between foreign-born and U.S.-born respondents $(P<$.05), except for gender. Of particular note, foreign-born respondents were younger, had lower annual household incomes, lower illness burdens, and poorer access to care.

Table 2 compares cancer screening by race/ethnicity and also by birthplace, using weighted analyses. We found significant differences by race/ethnicity and by birthplace in screening for all analyses performed $(P<.05)$. Compared to white respondents, blacks, Hispanics, and AAPIs were generally less likely to undergo Pap smears, mammograms,
FOBTs, and sigmoidoscopies. Similarly, compared with U.S.-born respondents, foreign-born respondents were also less likely to be screened with all forms of cancer screening.

\section{Differences in Screening by Race/Ethnicity}

We compared differences in screening for cervical, breast, and colorectal cancer by race/ethnicity, with white persons as the reference group, adjusting for sociodemographic characteristics and illness burden (Table 3). Black respondents were significantly more likely to report Pap smears and as likely to report mammography, FOBT, and sigmoidoscopy. Hispanic respondents were significantly less likely to report Pap smears, FOBT, or sigmoidoscopy, but as likely to report mammography. AAPI respondents were less likely to report all 4 screening outcomes; however, the difference for FOBT was not statistically significant.

\section{Differences in Screening by Race/Ethnicity After Accounting for Birthplace}

We then considered the combined influence of race/ ethnicity and birthplace on our 4 screening outcomes, using U.S.-born white respondents as the reference group. Prior to the first adjustment for sociodemographic characteristics, we checked for and established that there was no collinearity between education and income, and between concurrent illnesses, hospitalizations, and number of visits. As a result, we left all of the independent variables in each of the adjusted models. After adjusting for sociodemographic characteristics and illness burden, there were no significant differences in cancer screening in U.S.-born nonwhite respondents compared with U.S.-born white respondents with 1 exception. U.S.-born black respondents were significantly more likely to report Pap smears. Also of note, U.S.born AAPI respondents were more likely to report Pap-smears and less likely to report mammograms; however, neither of these results achieved statistical significance (Table 4).

In contrast, there were many differences in cancer screening between foreign-born respondents and U.S.-born white respondents after adjustment for sociodemographic factors and illness burden (Table 4). Foreign-born white women were significantly less likely to report Pap smears. Even after further adjustment for access to care, this difference persisted (adjusted odds ratio [AOR], 0.56; 95\% confidence interval [CI], 0.39 to 0.79). Foreign-born black respondents were significantly less likely to report FOBT; however, after further adjustment for access to care, this difference was attenuated and no longer significant (AOR, 0.51; 95\% CI, 0.21 to 1.21). Foreign-born Hispanic respondents were significantly less likely to report Pap smears, FOBT, and sigmoidoscopy. After further adjustment for access to care, differences were attenuated and were no longer statistically significant for Pap smears (AOR, 0.89; 95\% CI, 0.70 to 1.14), FOBT (AOR, 0.84; 95\% CI, 0.60 to 1.18), or sigmoidoscopy (AOR, 0.80; 95\% CI, 0.57 to 1.10 ). Last, foreign-born AAPI respondents were significantly less likely to report all 4 screening procedures. After 
Table 1. Comparison of Baseline Characteristic Between Foreign-born and U.S.-born Persons*

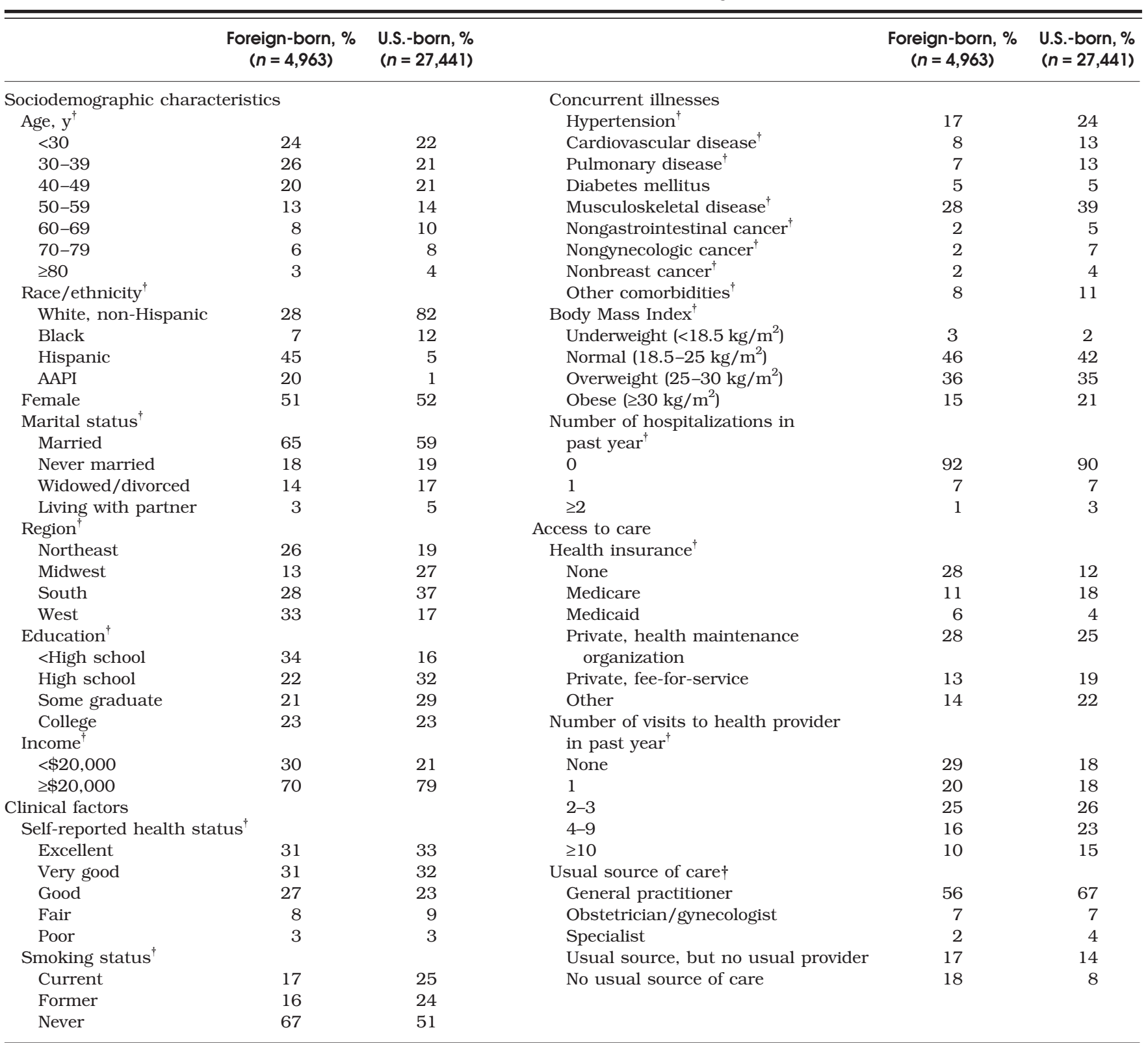

* All percentages are based on weighted analyses.

${ }^{\dagger} \mathrm{P}<.05$

further adjustment for access to care, foreign-born AAPI respondents remained significantly less likely to report Pap smears (AOR, 0.33; 95\% CI, 0.22 to 0.50); however, differences for mammography (AOR, 0.68; 95\% CI, 0.36 to 1.28 ), FOBT (AOR, 0.73; CI, 0.45 to 1.19), and sigmoidoscopy (AOR, 0.74; 95\% CI, 0.45 to 1.21 ) were attenuated and no longer statistically significant.

\section{Cancer Screening Among Hispanic Respondents}

Of the 5,155 Hispanic respondents in our study, 44\% were U.S. born and 56\% were foreign born. Among Hispanic respondents, 2,263 were eligible for cervical cancer screening, 550 were eligible for breast cancer screening, and 1,063 were eligible for colorectal cancer screening.

Foreign-born Hispanic women were significantly less likely to report cervical cancer screening than U.S.-born Hispanic women before and after adjustment for sociodemographic characteristics and illness burden; however, differences dissipated after additional adjustment for access to care (Table 5). Foreign-born Hispanic women were also significantly less likely to report breast cancer screening than U.S.-born Hispanic women before adjustment. After adjustment for sociodemographic characteristics and illness burden, however, the difference was attenuated and no longer statistically significant. Differences dissipated 
Table 2. Proportions Screened for Cancer by Race/Ethnicity and Birthplace*

\begin{tabular}{|c|c|c|c|c|}
\hline & $\begin{array}{l}\text { Pap Smear, } \\
\% \text { screened }\end{array}$ & $\begin{array}{l}\text { Mammogram, }^{\dagger} \\
\% \text { screened }\end{array}$ & $\begin{array}{l}\text { Fecal Occult Blood } \\
\text { Test, }^{\dagger} \% \text { screened }\end{array}$ & $\begin{array}{l}\text { Sigmoidoscopy, } \\
\% \text { screened }\end{array}$ \\
\hline Overall & 84 & 72 & 27 & 29 \\
\hline White, non-Hispanic & 86 & 74 & 28 & 30 \\
\hline Black & 88 & 70 & 24 & 26 \\
\hline Hispanic & 77 & 66 & 18 & 20 \\
\hline U.S.-born & 86 & 73 & 27 & 30 \\
\hline Foreign-born & 74 & 66 & 21 & 23 \\
\hline
\end{tabular}

* All percentages are based on weighted analyses.

${ }^{\dagger} \mathrm{P}<.005$ for each type of cancer screening by both race/ethnicity and birthplace.

Table 3. Multivariable Analysis of Relation Between Race/Ethnicity and Screening for Cervical, Breast, and Colorectal Cancer* $^{*}$

\begin{tabular}{|c|c|c|c|c|}
\hline White & 1.00 & 1.00 & 1.00 & 1.00 \\
\hline Black & $2.34(1.76 \text { to } 3.11)^{\dagger}$ & $1.21(0.93$ to 1.56$)$ & $1.01(0.83$ to 1.22$)$ & $1.11(0.89$ to 1.37$)$ \\
\hline Hispanic & $0.79(0.67 \text { to } 0.94)^{\dagger}$ & $0.97(0.72$ to 1.30$)$ & $0.75(0.59 \text { to } 0.94)^{\dagger}$ & $0.77(0.62$ to 0.96$)$ \\
\hline
\end{tabular}

* Analysis adjusted for sociodemographic characteristics (age, marital status, region of residence, education, income) and illness burden (selfreported health status, smoking, concurrent illnesses, body mass index, hospitalizations in past year).

${ }^{\dagger} \mathrm{P} \leq .05$

AOR, adjusted odds ratio; CI, confidence interval.

Table 4. Multivariable Analysis of Relation Between Combined Birthplace and Race/Ethnicity and Screening for Cervical, Breast, and Colorectal Cancer, ${ }^{*}$

\begin{tabular}{|c|c|c|c|c|}
\hline & $\begin{array}{l}\text { Pap Smear, } \\
N=10,486 \\
\text { AOR }(95 \% \mathrm{Cl})\end{array}$ & $\begin{array}{c}\text { Mammogram, } \\
N=4,597 \\
\text { AOR }(95 \% \mathrm{Cl})\end{array}$ & $\begin{array}{c}\text { Fecal Occult Blood Test, } \\
N=9,823 \\
\text { AOR }(95 \% \mathrm{Cl})\end{array}$ & $\begin{array}{c}\text { Sigmoidoscopy, } \\
\qquad N=9,968 \\
\text { AOR }(95 \% \mathrm{Cl})\end{array}$ \\
\hline White & 1.00 & 1.00 & 1.00 & 1.00 \\
\hline Black & $2.44(1.81 \text { to } 3.28)^{\ddagger}$ & $1.18(0.91$ to 1.53$)$ & 1.05 (0.86 to 1.28$)$ & 1.15 (0.92 to 1.43$)$ \\
\hline Hispanic & $0.94(0.74$ to 1.20$)$ & $1.17(0.76$ to 1.80$)$ & 0.77 (0.56 to 1.05$)$ & 0.85 (0.64 to 1.13$)$ \\
\hline White & $0.58(0.41 \text { to } 0.82)^{\ddagger}$ & $0.86(0.60$ to 1.23$)$ & $0.83(0.64$ to 1.07$)$ & $0.98(0.75$ to 1.28$)$ \\
\hline Black & $1.05(0.49$ to 2.24$)$ & $1.62(0.53$ to 4.99$)$ & $0.40(0.18 \text { to } 0.88)^{\ddagger}$ & $0.48(0.21$ to 1.09$)$ \\
\hline Hispanic & $0.65(0.53 \text { to } 0.79)^{\ddagger}$ & $0.84(0.58$ to 1.22$)$ & $0.72(0.53 \text { to } 0.98)^{\ddagger}$ & $0.70(0.51 \text { to } 0.97)^{\ddagger}$ \\
\hline AAPI & $0.28(0.19 \text { to } 0.39)^{\ddagger}$ & $0.49(0.28 \text { to } 0.86)^{\ddagger}$ & $0.61(0.39 \text { to } 0.96)^{\ddagger}$ & $0.63(0.40 \text { to } 0.99)^{\ddagger}$ \\
\hline
\end{tabular}

* Analysis adjusted for sociodemographic characteristics (age, marital status, region of residence, education, income), and illness burden (selfreported health status, smoking, concurrent illnesses, body mass index, hospitalizations in past year).

${ }^{\dagger}$ Unadjusted odds ratios did not differ substantially from the adjusted odds ratios presented in this table.

${ }^{\ddagger} \mathrm{P} \leq .05$.

AOR, adjusted odds ratio; CI, confidence interval. 
Table 5. Multivariable Analysis of Relation Between Birthplace and Screening Among Hispanic and Asian-American Pacific Islander Respondents

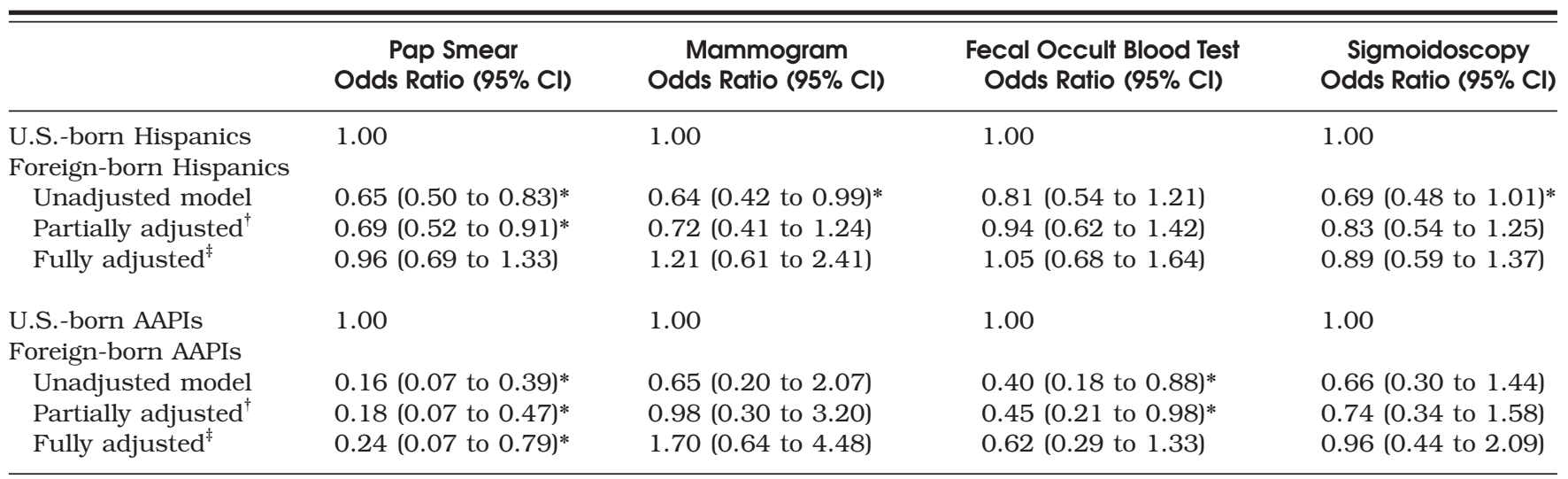

$* \mathrm{P} \leq .05$

${ }^{\dagger}$ Analysis adjusted for sociodemographic characteristics (age, marital status, region of residence, education, income) and illness burden (selfreported health status, smoking, concurrent illnesses, body mass index, hospitalizations in past year).

${ }^{\ddagger}$ Additionally adjusted for access to care (number of office visits in past year, type of health insurance, usual source of care).

CI, confidence interval.

further after additional adjustment for access to care. Before adjustment, foreign-born Hispanic respondents were as likely to report FOBT, but significantly less likely to report sigmoidoscopy compared with U.S.-born Hispanic respondents. Differences for sigmoidoscopy use were substantially attenuated after adjustment and were no longer statistically significant (Table 5).

\section{Cancer Screening Among Asian-American/ Pacific Islander Respondents}

Of the 850 AAPI respondents, 21\% were U.S. born and $79 \%$ were foreign born; 344 were eligible for cervical cancer screening, 95 were eligible for breast cancer screening, and 192 were eligible for colorectal cancer screening. Compared with U.S.-born AAPI women, foreign-born AAPI women were significantly less likely to be screened for cervical cancer, even after adjustment for sociodemographic characteristics, illness burden, and additional adjustment for access to care (Table 5). Although foreign-born AAPI women were less likely to report mammography than U.S.-born AAPI women, the difference was not statistically significant. The sample size of U.S.-born AAPI women eligible for breast cancer screening was small $(n=25)$, and additional analyses were difficult to interpret because of the wide confidence intervals. Foreign-born AAPI respondents were also significantly less likely to report FOBT than U.S.-born AAPI respondents, before and after adjustment for sociodemographic characteristics and illness burden. After additional adjustment for access to care, the association between foreign birth and FOBT was substantially attenuated, and was no longer statistically significant (Table 5).

\section{DISCUSSION}

Our study suggests that foreign birth explains some differences in cancer screening previously attributed to race and ethnicity. In our initial analyses, we found that Hispanic and AAPI persons were significantly less likely to receive many forms of cancer screening than white persons, despite adjustments for sociodemographic factors and illness burden. After accounting for birthplace, we found that U.S.-born Hispanic and AAPI persons were generally as likely to report screening as U.S.-born whites, but that foreign-born Hispanic and AAPI persons were significantly less likely to report many forms of cancer screening, suggesting that previous differences attributed to race and ethnicity were driven largely by birthplace. Access to health care appears to explain some, but not all of the observed differences in screening between foreign-born and U.S.born persons. In particular, the influence of access to health care was more pronounced among foreign-born Hispanic persons than foreign-born AAPI persons.

Consistent with prior studies, our initial analyses confirm that Hispanic and AAPI persons living in the United States are less likely to report cancer screening. These racial and ethnic disparities were previously attributed to differences in factors such as income, education, geographic residence, and health care access. ${ }^{7-10,22-27}$ In our study, adjusting for access to care attenuated differences in screening by race and ethnicity, but socioeconomic factors such as education and income did not play a major role.

Our analyses examining the influence of birthplace also confirm prior studies which show that racial/ethnic subgroups comprised largely of immigrants have lower screening rates for cervical, breast, and colorectal cancer. ${ }^{2-7}$ One hypothesis for this screening disparity may be that foreign-born persons are disproportionately affected by barriers such as lower income, less education, and lack of access to care. While some demographic and socioeconomic barriers are more prevalent among foreign-born persons, our study demonstrates differences by birthplace persisted even after accounting for factors such as education and 
income. In addition, while adjusting for access to care substantially attenuated differences between foreign-born and U.S.-born Hispanic persons, it did not explain the large difference between foreign-born and U.S.-born AAPI persons.

Previous studies suggest that immigrants may experience unique barriers to care..$^{2-11,17,18,23,24,28-30}$ Language and cultural differences between immigrants and health care providers may lead to poorer communication about the importance of cancer screening, and result in lower screening rates. ${ }^{9,15-18}$ Additional barriers may include provider characteristics such as gender and ethnicity, as seen in studies demonstrating that AAPI women cared for by female or non-AAPI physicians have higher rates of cervical and breast cancer screening. ${ }^{8,9,23}$ Whether these factors are important among non-AAPI immigrant groups is unclear. Acculturation factors such as number of years in the United States and cultural preferences associated with country of origin may influence cancer screening and are deserving of further study.

Clarifying the relationship between race, ethnicity, and foreign birth is important because it may help identify specific barriers faced by these at-risk populations, and can create opportunities to intervene and improve health. Cancer screening leads to earlier identification and treatment of disease, and ultimately to lower mortality. ${ }^{28-33}$ Some data suggest that immigrants present at more advanced stages of disease and have poorer survival because of advanced stage at presentation. ${ }^{6,34-36}$ Therefore, identifying specific areas of intervention may ultimately lead to improved morbidity and mortality.

Based on our findings, one of the barriers disproportionately affecting foreign-born persons, especially foreignborn Hispanics, is poor access to health care. Improving access by providing health insurance coverage, encouraging the identification of a primary care provider, and teaching the benefits of annual well visits may increase screening. Access to care, however, may only be one of many factors affecting cancer screening.

The observation that for AAPI persons the disparity in cervical cancer screening is not accounted for by access to care suggests that there may be additional cultural barriers to care that require exploration. Further research should focus on factors that may be specific to immigrants, such as the influence of limited English proficiency and poor access to culturally competent health care providers. Additionally, general factors that may have unique effects on immigrants deserve study, such as lack of knowledge about the benefits of cancer screening, the effects of provider gender and race/ethnicity, amount of time spent with patients, frequency with which cancer screening is offered, and subsequent patient responses to screening recommendations. Potential interventions include improving interpreter services, reducing geographic barriers (such as distance, accessibility by public transportation, etc.), and targeting health care providers to educate their immigrant patients about the benefits of cancer screening and repeatedly offer screenings.
Although we utilized a nationally generalizable population, our study has limitations. First, the National Health Interview Survey (NHIS) relies exclusively on patient-reported information, which may lead to recall bias. We attempted to minimize recall bias by choosing the most lenient cancer screening criteria recommended, and adjusting for educational differences. Another limitation was potentially increased nonresponse from non-English, non-Spanish speakers. We were unable to identify which respondents used translators or the respondent's language proficiency, and therefore could not adjust for this variable. Additionally, these procedures may have resulted in an increased nonresponse from households where no family members spoke English or Spanish. This nonresponse would likely bias our findings toward the null, thus underestimating the relationship between cancer screening and foreign birth found in our study. Immigrants are a heterogeneous population with different levels of acculturation, which were not measured directly in this survey. In the future, we would like to explore this further when improved information about the number of years in the United States and language proficiency becomes available. It is possible that acculturation patterns may affect screening patterns differently in different ethnic subgroups. We did not have adequate sample sizes to pursue additional analyses in the majority of Hispanic and Asian ethnic subgroups.

In summary, foreign birth may be a barrier to some forms of cancer screening, and may explain some disparities previously attributed to race or ethnicity. Although improving access to care may attenuate some of the differences observed between foreign-born and U.S.-born persons, particularly among foreign-born Hispanic persons, additional research is needed to explore causal factors for differences in cancer screening, especially for foreign-born AAPI persons. In the interim, foreign-born persons should be targeted for improved health care access and appropriate cancer screening.

Dr. Goel is supported by an institutional National Research Service Award (5T32PE 1 1001-13) and by the Ryoichi Sasakawa Fund. Dr. Wee is supported by a career development award from the National Institute of Diabetes, Digestive and Kidney Diseases (K23DK02962-02). Dr. McCarthy is the recipient of a First Independent Research and Transition Award from the National Cancer Institute (R29 CA79052). Dr. Ngo-Metzger is supported by the National Cancer Institute Asian American Network for Cancer Awareness, Research and Training (U01 CA86322). Dr. Phillips is supported by a Mid-Career Investigator Award from the National Institutes of Health (K24 AT00589-01A1).

The authors gratefully acknowledge Dr. Lisa lezzoni for review of an earlier draft.

\section{REFERENCES}

1. Schmidley AD. Profile of the Foreign-Born Population in the United States: 2000. US Census Bureau, Current Population Reports. Series P23-206. Washington, DC: US Government Printing Office; 2001.

2. Fruchter RG, Remy JC, Burnett WS, Boyce JG. Cervical cancer in 
immigrant Caribbean women. Am J Public Health 1986;67:797-9.

3. Maxwell AE, Bastani R, Warda US. Demographic predictors of cancer screening among Filipino and Korean immigrants in the United States. Am J Prev Med. 2000;18:62-8.

4. Tu SP, Yasui Y, Kuniyuki A, et al. Breast cancer screening among Cambodian American women. Cancer Detect Prev. 2000;24:549-63.

5. Taylor VM, Schwartz SM, Jackson JC, et al. Cervical cancer screening among Cambodian American women. Cancer Epidemiol Biomarkers Prev. 1999;8:541-6.

6. Fruchter RG, Wright C, Habenstreit B, Remy JC, Boyce JG, Imperato PJ. Screening for cervical and breast cancer among Caribbean immigrants. J Community Health 1985;10:121-35.

7. Schulmeister L, Lifsey DS. Cervical cancer screening knowledge, behaviors, and beliefs of Vietnamese women. Oncol Nurs Forum. 1999;26:879-87.

8. Kagawa-Singer M, Pourat N. Asian American and Pacific Islander breast and cervical carcinoma screening rates and healthy people 2000 objectives. Cancer 2001;89:696-705.

9. Fulton JP, Rakowski W, Jones AC. Determinants of breast cancer screening among inner-city Hispanic women in comparison with other inner-city women. Public Health Rep. 1995;110:476-82.

10. Perez-Stable EJ, Otero Sabogal R, Sabogal F, Mcphee SJ, Hiatt RA. Self-reported use of cancer screening tests among Latinos and Anglos in a prepaid health plan. Arch Intern Med. 1994;154:1073-81.

11. Coughlin SS, Uhler RJ. Breast and cervical cancer screening practices among Hispanic women in the United States and Puerto Rico, 1998-99. Prev Med. 2002;34:242-51.

12. Coughlin SS, Uhler RJ. Breast and cervical cancer screening practices among Asian and Pacific Islander women in the United States, 1994-1997. Cancer Epidemiol Biomarkers Prev. 2000;9:597-603.

13. Thamer M, Rinehart C. Public and private health insurance of US foreign-born residents: implications of the 1996 welfare reform law. Ethn Health. 1998;3:19-29.

14. Ku L, Matani S. Left out: immigrants' access to health care and insurance. Health Aff. 2001;20:247-56.

15. Fox SA. The importance of physician communication on breast cancer screening of older women. Arch Intern Med. 1994;154:205868.

16. Fox SA. The effect of physician-patient communication on mammography utilization by different ethnic groups. Med Care. 1991; 1065-82.

17. Woloshin S, Schwartz LM, Katz SJ, Welch HG. Is language a barrier to the use of preventive services? J Gen Intern Med. 1997;12:472-7.

18. Solis JM, Marks G, Garcia M, Shelton D. Acculturation, access to care, and use of preventative services by Hispanics: findings from HHANES 1982-1984. Am J Public Health. 1990;80(suppl):11-9.

19. National Center for Health Statistics. 1998 National Health Interview Survey. Available at: http://www.cdc.gov/nchs/nhis.htm. Accessed June 10, 2002
20. US Preventive Services Task Force. Guide to Clinical Preventive Services. 2nd ed. Baltimore: Williams \& Wilkins; 1996.

21. Shah BV, Barnwell BG, Bieler GS. SUDAAN User's Manual. Release 7.5. NC: Research Triangle Institute, Research Triangle Park; 1997.

22. Juon HS, Choi Y, Kim MT. Cancer screening behaviors among Korean-American women. Cancer Detect Prev. 2000;24:589-601.

23. Mcphee SJ, Stewart S, Brock KC, Bird JA, Jenkins CN, Pham GQ. Factors associated with breast and cervical cancer screening practices among Vietnamese American women. Cancer Detect Prev. 1997; 1:510-21.

24. Shankar S, Figueroa-Valles N. Cancer knowledge and misconceptions: a survey of immigrant Salvadorean women. Ethn Dis. 1999;9:20111

25. Phipps E, Cohen MH, Sort R, Braitman LE. A pilot study of cancer knowledge and screening behaviors of Vietnamese and Cambodian women. Health Care Women Int. 1999;20:195-207.

26. Tanjasiri SP, Sablan-Santos L. Breast cancer screening among Chamorro women in southern California. J Womens Health Gend Based Med. 2001;10:479-85.

27. Peragallo NP, Fox PG, Alba ML. Breast care among Latino immigrant women in the US. Health Care Women Int. 1998;19:165-72.

28. Pettersson F, Bjorkholm E, Naslund I. Evaluation of screening for cervical cancer in Sweden: trends in incidence and mortality 195880. Int J Epidemiol. 1985; 14:521-7.

29. Sobue T, Suzuki T, Hashimoto S, Yokoi N, Fujimoto I. A case-control study of the effectiveness of cervical cancer screening in Osaka, Japan. Jpn J Cancer Res. 1988;79:1269-75.

30. Anonymous. Update: National breast and cervical cancer early detection program: July 1991-September 1995. MMWR. 1996;45: 484-7.

31. Nystron L, Andersson I, Bjurstam N, Frisell J, Nordenskjold B, Rutqvist LE. Long-term effects of mammography screening: updated overview of the Swedish randomised trials. Lancet. 2002;359:909-19.

32. Jorgensen OD, Kronborg O, Fenger C. A randomised study of screening for colorectal cancer using faecal occult blood testing: results after 13 years and seven biennial screening rounds. Gut. 2002;50:29-32.

33. Selby JV, Friedman GD, Quesenberry CP, Weiss NS, Quesenberry CP Jr. A case-control study of screening sigmoidoscopy and mortality from colorectal cancer. N Engl J Med. 1992;326:653-7.

34. Choe JH, Koepsell TD, Heagerty PJ. Differences in colorectal cancer survival between foreign-born and US-born Asian Americans and Pacific Islanders. J Gen Intern Med. 2002;17(suppl): 154 (Abstract).

35. Hedeen AN, White E, Taylor V. Ethnicity and birthplace in relation to tumor size and stage in Asian American women with breast cancer. Am J Public Health. 1999;89:1248-52.

36. Hedeen AN, White E. Breast cancer size and stage in Hispanic American women, by birthplace: 1992-95. Am J Public Health. 2001:91:122-5. 